UDC 349.4

LBC 67.407

\title{
REVISITING THE TRENDS IN LEGAL REGULATION PARCELLING-OUT OF LAND FOR DEVELOPMENT PURPOSES
}

\author{
Oksana I. Sharno \\ Volgograd State University, Volgograd, Russian Federation \\ Sergey A. Frolov \\ OP Uran-1 Ltd., Volgograd, Russian Federation
}

\begin{abstract}
Introduction: the article considers problems of legal regulation of the provision of land, analyzed the order of formation and granting of lands of state and municipal property to physical and legal persons, the abolition of the gradation of the purposes of the provision of land plots (for construction and without). For this purpose, the author analyzes a single procedure for granting land plots from state and municipal property for all purposes. Applied in conjunction methods of scientific knowledge, including basic methods of system analysis and comparative-legal. Results: the author analyzed single procedure for granting land plots from state and municipal property for all purposes. Relationship for the provision of land for construction are divided into two groups: the formation of a land plot from public lands and transfer the land to the person concerned in accordance with one of the established land legislation procedures. Conclusions: the author comes to the conclusion that it is premature to fully assess the land reform in providing land plots from state and municipal property to physical and legal persons.
\end{abstract}

Key words: land, construction, development, urban planning, state and municipal lands, land reform.

УДК 349.4

ББК 67.407

\section{К ВОПРОСУ О ТЕНДЕНЦИЯХ ПРАВОВОГО РЕГУЛИРОВАНИЯ ПРЕДОСТАВЛЕНИЯ ЗЕМЕЛЬНЫХ УЧАСТКОВ ПОД СТРОИТЕЛЬСТВО}

\author{
Оксана Игоревна Шарно \\ Волгоградский государственный университет, г. Волгоград, Российская Федерация
}

Сергей Александрович Фролов

ООО «ОП “Уран-1”», г. Волгоград, Российская Федерация

\footnotetext{
Введение: в статье рассматриваются проблемы правового регулирования предоставления земельных участков, анализируется порядок формирования и предоставления земель из государственной и муниципальной собственности физическим и юридическим лицам, отмена градации целей предоставления земельных участков (для строительства и без такового). С этой целью автор анализирует единый порядок предоставления земельных участков из государственной и муниципальной собственности для всех целей использования. Применены в совокупности методы научного познания, среди которых основные - методы системности, анализа и сравнительно-правовой. Результаты: автором проанализирован единый порядок предоставления земельных участков из государственной и муниципальной собственности для всех целей использования. Правоотношения по предоставлению земельных участков для строительства разделены на две группы: по образованию земельного участка из публичных земель и по передаче земельного участка заинтересованному лицу в соответствии с одной из установленных земельным законодательством процедур. Выводы: автор приходит к выводу о преждевременности полноценной оценки земельной реформы в части предоставления земельных участков из государственной и муниципальной собственности физическим и юридическим лицам.

Ключевые слова: земельные участки, строительство, градостроительная деятельность, земли государственной и муниципальной собственности, земельная реформа.
} 
К вопросу о тенденциях правового регулирования предоставления земельных участков под строительство

\section{Введение}

С 1 марта 2015 г. изменилось правовоерегулирование предоставления земельных участков, находящихся в государственной и муниципальной собственности для целей строительства. Нововведения внедряются в России поэтапно, в отношении регулирования предоставления земельных участков для строительства, предпринятого до 1 марта 2015 г., установлен «переходный период» [12], в течение которого в ряде случаев остались применимы нормы ЗК РФ [7]. Данные обстоятельства обусловили актуальность настоящей статьи.

\section{Основное содержание}

Под предоставлением земельных участков для строительства понимаются «общественные отношения, урегулированные нормами земельного права и законодательства о градостроительной деятельности, которые возникают, существуют и прекращаются в связи с образованием земельного участка (в том числе искусственного), последующей его передачей органами государственной власти и местного самоуправления участникам земельных отношений в целях создания на нем зданий, строений и сооружений» [4, с. 13$]$.

С 23 июня 2014 г. вступил в силу новый порядок формирования и предоставления земель из государственной и муниципальной собственности физическим и юридическим лицам. Нововведения призваны сделать прозрачным процесс приобретения участков в аренду и в собственность. Ранее ЗК РФ предусматривал несколько различных процедур предоставления земельных участков в зависимости от цели предоставления: для строительства (ст. 30, 30.1, 30.2, 31 ЗК РФ) и для иных целей, не связанных со строительством (ст. 34 ЗК РФ). С 1 марта 2015 г. утвержден единый порядок предоставления земельных участков из государственной и муниципальной собственности для всех целей использования (формулировки целей предоставления «для строительства» и «не связанных со строительством» исключены) [2], то есть объединены предусмотренные ЗК РФ процедуры предоставления земельных участков для строительства с предварительным согласованием места размещения объекта и без такового с процедурой предоставления земельных участков для целей, не связанных со строительством [21].

Достижение единого порядка предоставления земельных участков из государственных и муниципальных земель вне зависимости от цели их предоставления в доктрине земельного права не оценивается однозначно. Д.С. Железнов отмечает, что в результате изменений «целевые» статьи из ЗК РФ практически полностью исключены [4]. Е.А. Прокошева выделяет [11]: отмену градации целей предоставления земельных участков (на цели, связанные со строительством, и не связанные с таковым), за исключением ряда случаев [7], свидетельствующих, что способ предоставления участка все-таки зависит от целей его использования, поскольку не учитывать конкурентную среду, в которой осуществляется строительство, выступающее как вид предпринимательской деятельности, нерационально; отмену процедур административного санкционирования, связанных с согласованиями и утверждением акта выбора земельного участка $[7 ; 8]$. Анализ принятых на региональном уровне нормативных актов $[5 ; 6]$ позволяет сделать вывод о том, что установленные в них критерии и механизм их определения различны, как отличаются и особенности предоставления земельных участков для строительства в городах федерального значения (Москве, Санкт-Петербурге и Севастополе) [3].

Действующим земельным законодательством урегулировано выделение следующих процедур предоставления земельных участков [2]: на аукиионе (без предварительного согласования) (п. 2 ст. 39.1 , п. 7 ст. 39.11 ЗК РФ, искл. ст. 39.18 ЗК РФ); без аукииона (с предварительным согласованием) (пп. 1 п. 1 ст. 30 , пп. 3 п. 1 ст. 39.14 ЗК РФ); без аукииона и без предварительного согласования (п. 2 ст. 39.3 , п. 2 ст. 39.6, п. 2 ст. 39.9, п. 2 ст. 39.10); на аукиионе (с предварительным согласованием) (ст. 39.18 ЗК РФ).

Следовательно, правоотношения по предоставлению земельных участков для строительства включают в себя две группы отношений: по образованию земельного участка из публичных земель (земельного участка), по его передаче заинтересованному лицу в 
соответствии с одной из установленных земельным законодательством процедур.

Земельные участки для целей строительства предоставляются на территории Волгограда и Волгоградской области в соответствии с утвержденными административными регламентами $[9 ; 10]$, при этом информирование населения о предоставляемых земельных участках для строительства производится до предоставления земельного участка под строительство [1]. Информация о продаже земельных участков и заключении договоров аренды земельных участков размещается в источниках информирования в соответствии с требованиями ст. 39.11-39.13 и 39.18 ЗК РФ. Относительно предоставления земельных участков в Волгоградской области для строительства определены случаи и основания предоставления земельных участков, находящихся в государственной или муниципальной собственности, на территории Волгоградской области в собственность граждан бесплатно (до 1 января 2019 года).

Правообразующим юридическим составом, влекущим возникновение правоотношений по предоставлению земельных участков для строительства, является подготовка и утверждение уполномоченным органом власти схемы расположения земельного участка, либо подготовка и утверждение проекта межевания [2]. Юридическим фактом, влекущим прекращение рассматриваемых правоотношений, является вынесение органом государственной власти или местного самоуправления решения о предоставлении земельного участка в собственность бесплатно, в постоянное (бессрочное) пользование (пп. 1 п. 1 ст. 39.1 ЗК РФ), либо заключение договора купли-продажи, аренды или безвозмездного пользования (пп. 2-4 п. 1 ст. 39.1 ЗК РФ). При этом в случае необходимости проведения государственной регистрации перехода права или сделки (например, договора купли-продажи земельного участка или договора аренды, заключенного сроком более одного года), прекращение таких правоотношений будет связано с юридическим составом.

\section{Заключение}

Законодатель с целью усовершенствования процедуры предоставления земельных участков, градостроительного регулирования предпринял попытку унифицировать и минимизировать процедуры предоставления для строительства земельных участков, находящихся в государственной или муниципальной собственности. Вовлечение достаточно большого количества участков в гражданский оборот путем упрощения процедур предоставления земельных участков характеризуется органами государственной власти и местного самоуправления положительно, как получение дополнительного дохода. Однако формулировать оценку правореализационным и правоприменительным реалиям земельной реформы в рассматриваемой области, на наш взгляд, пока преждевременно.

\section{СПИСОК ЛИТЕРАТУРЫ}

1. Васильев, Э. Х. Правовые механизмы обеспечения прав граждан при предоставлении земель для строительства объектов недвижимости / Э. Х. Васильев // Современное право. - 2014. - № 1. - С. 70-74.

2. Железнов, Д. С. Новеллы правового регулирования предоставления земельных участков для строительства в свете ключевых положений Ф3 от 23.06.2014 г. № 171-Ф3 / Д. С. Железнов // Аграрное и земельное право. - № 11 (119). - 2014. - С. 43-51.

3. Железнов, Д. С. Особенности предоставления земельных участков для строительства в городах федерального значения Москве, Санкт-Петербурге и Севастополе / Д. С. Железнов // Аграрное и земельное право. - 2015. - № 1. - С. 24-31.

4. Железнов, Д. С. Правоотношения по предоставлению земельных участков для строительства: понятие, структура, элементы / Д. С. Железнов // Аграрное и земельное право. - 2015. - № 5 (125). C. $12-16$.

5. Закон Белгородской области «Об установлении критериев, которым должны соответствовать объекты социально-культурного и коммунальнобытового назначения, инвестиционные проекты, для размещения (реализации) которых земельные участки предоставляются в аренду без проведения торгов» от 3 апреля 2015 г. № 345 // Официальный интернет-портал правовой информации. - Электрон. текстовые дан. - Режим доступа: http://www. pravo.gov.ru/. - Загл. с экрана.

6. Закон Волгоградской области «Об установлении критериев, которым должны соответствовать объекты социально-культурного и коммунальнобытового назначения, масштабные инвестиционные проекты, для размещения (реализации) кото- 
рых земельные участки предоставляются в аренду без проведения торгов» от 30 июня 2015 г. № 85-ОД // Официальный интернет-портал правовой информации. - Электрон. текстовые дан. - Режим доступа: http://www.pravo.gov.ru/. - Загл. с экрана.

7. Земельный кодекс Российской Федерации от 25 октября 2001 г. № 136-Ф3 // Российская газета. - 2001. -30 октября (№ 2823).

8. Орешкина, О. В. Правовое обеспечение предоставления и изъятия земель : автореф. дис. ... канд. юрид. наук / Орешкина Ольга Викторовна. Саратов, 2004. - 24 c.

9. Постановление Администрации Волгограда «Об утверждении Административного регламента предоставления муниципальной услуги "Предоставление земельных участков, государственная собственность на которые не разграничена, а также земельных участков, находящихся в муниципальной собственности Волгограда, в собственность за плату без проведения торгов”» от 22 июня 2015 г. № 862 // Информационно-правовая система «Законодательство России». - Электрон. текстовые дан. - Режим доступа: http://pravo.gov.ru/proxy/ips/ ?start_search\&fattrib=1. - Загл. с экрана.

10. Приказ Комитета по управлению государственным имуществом Волгоградской области «Об утверждении Административного регламента предоставления комитетом по управлению государственным имуществом Волгоградской области государственной услуги “Предоставление земельных участков в собственность и в аренду гражданам и юридическим лицам без проведения торгов"» от 15 июля 2015 г. № 17-н // Информационный портал Волгоградской области. - Электрон. текстовые дан. - Режим доступа: http://volgograd.regnews.org/ doc/vq/hf.htm. - Загл с экрана.

11. Прокошева, Е. А. Особенности и некоторые проблемы административного санкционирования при предоставлении земельных участков для строительства в условиях земельной реформы / Е. А. Прокошева // Юридический мир. - М. : Юрист, 2016. № 7 -С. 49-52.

12. Федеральный закон «О внесении изменений в Земельный кодекс Российской Федерации и отдельные законодательные акты Российской Федерации» от 23 июня 2014 г. № 171-Ф3 (ред. от 29 июля 2017 г.) // Собрание законодательства РФ. 2014. - № 26-Ст. 3377.

\section{REFERENCES}

1. Vasilyev E.Kh. Pravovye mekhanizmy obespecheniya prav grazhdan pri predostavlenii zemel dlya stroitelstva obyektov nedvizhimosti [Legal
Mechanisms of Ensuring the Rights of Citizens in the Provision of Lands for the Construction of Real Estate]. Sovremennoe pravo, 2014, no. 1, pp. 70-74.

2. Zheleznov D.S. Novelly pravovogo regulirovaniya predostavleniya zemelnykh uchastkov dlya stroitelstva v svete klyuchevykh polozheniy FZ ot 23.06.2014 g. №171-FZ [Novels of Legal Regulation of Land Plots Provision for Construction in the Light of Key Provisions of the Federal Law of June 23, 2014 no. 171-FL]. Agrarnoe i zemelnoe pravo, 2014, no. 11 (119), pp. 43-51.

3. Zheleznov D.S. Osobennosti predostavleniya zemelnykh uchastkov dlya stroitelstva $\mathrm{v}$ gorodakh federalnogo znacheniya - Moskve, Sankt-Peterburge i Sevastopole [The Provision of Land Plots for Construction in Cities of Federal Significance Moscow, Saint Petersburg and Sevastopol]. Agrarnoe i zemelnoe pravo, 2015, no. 1, pp. 24-31.

4. Zheleznov D.S. Pravootnosheniya po predostavleniyu zemelnykh uchastkov dlya stroitelstva: ponyatie, struktura, elementy [Legal Relations in the Sphere of Land Provision for Construction: Concept, Structure, Elements]. Agrarnoe i zemelnoe pravo, 2015, no. 5 (125), pp. 12-16.

5. Zakon Belgorodskoy oblasti «Ob ustanovlenii kriteriev, kotorym dolzhny sootvetstvovat obyekty sotsialno-kulturnogo i kommunalno-bytovogo naznacheniya, investitsionnye proekty, dlya razmeshcheniya (realizatsii) kotorykh zemelnye uchastki predostavlyayutsya $\mathrm{v}$ arendu bez provedeniya torgov» ot 3 aprelya 2015 g. № 345 [Law of the Belgorod Region "On Establishing Criteria for the Objects of Socio-Cultural and CommunalHousehold Purposes, Investment Projects for the Allocation (Sale) of Which Land Plots Are Leased Without Holding Tenders" of April 3, 2015 no. 345]. Ofitsialnyy internet-portal pravovoy informatsii [Official Web-Portal of Legal Information]. URL: http:// www.pravo.gov.ru/.

6. Zakon Volgogradskoy oblasti «Ob ustanovlenii kriteriev, kotorym dolzhny sootvetstvovat obyekty sotsialno-kulturnogo i kommunalno-bytovogo naznacheniya, masshtabnye investitsionnye proekty, dlya razmeshcheniya (realizatsii) kotorykh zemelnye uchastki predostavlyayutsya $\mathrm{v}$ arendu bez provedeniya torgov» ot 30 iyunya 2015 g. № 85-OD [Law of the Volgograd region "On Establishing Criteria for the Objects of Socio-Cultural and Communal-Household Purposes, Investment Projects for the Allocation (Sale) of Which Land Plots Are Leased Without Holding Tenders" of June 30, 2015 no. 85-OD]. Ofitsialnyy internet-portal pravovoy informatsii [Official WebPortal of Legal Information]. URL: http://www. pravo.gov.ru/.

7. Zemelnyy kodeks Rossiyskoy Federatsii ot 25 oktyabrya 2001 g. № 136-FZ [The Land Code of the 
Russian Federation of October 25, 2001 no. 136-FL]. Rossiyskaya gazeta, 2001, October 30 (no. 2823).

8. Oreshkina O.V. Pravovoe obespechenie predostavleniya i izyatiya zemel: avtoref. dis. ... kand. yurid. nauk [Legal Grounds for Granting and Withdrawal of Lands. Cand. jurid. sci. abs. diss.]. Saratov, 2004. 24 p.

9. Postanovlenie Administratsii Volgograda $« \mathrm{Ob}$ utverzhdenii Administrativnogo reglamenta predostavleniya munitsipalnoy uslugi "Predostavlenie zemelnykh uchastkov, gosudarstvennaya sobstvennost na kotorye ne razgranichena, a takzhe zemelnykh uchastkov, nakhodyashchikhsya $\mathrm{v}$ munitsipalnoy sobstvennosti Volgograda, v sobstvennost za platu bez provedeniya torgov"» ot 22 iyunya 2015 g. № 862 [Decree of the Administration of Volgograd "On Approval of the Administrative Regulations for the Provision of Municipal Service 'Provision of Land Plots Whose State Ownership Is Not Delimited, as Well as Land Plots that Are in the Municipal Property of Volgograd, into Ownership for a Fee Without Holding Tenders"” of June 22, 2015 no. 862]. Informatsionno-pravovaya sistema "Zakonodatelstvo Rossii» [Information and Legal System "Russian Legislation"]. URL: http:// pravo.gov.ru/proxy/ips/?start_search\&fattrib=1.

10. Prikaz Komiteta po upravleniyu gosudarstvennym imushchestvom Volgogradskoy oblasti «Ob utverzhdenii Administrativnogo reglamenta predostavleniya komitetom po upravleniyu gosudarstvennym imushchestvom Volgogradskoy oblasti gosudarstvennoy uslugi "Predostavlenie zemelnykh uchastkov v sobstvennost i v arendu grazhdanam i yuridicheskim litsam bez provedeniya torgov”» ot 15 iyulya 2015 g. № 17-n [Order of the Committee for the Management of State Property of the Volgograd Region "On Approval of the Administrative Regulations for the Provision by the State Property Committee of the Volgograd Region of the State Service 'Provision of Land Plots in Ownership and Leases to Citizens and Legal Entities without Holding Trades"” of July 15, 2015 no. 17-n]. Informatsionnyy portal Volgogradskoy oblasti [Information Portal of the Volgograd Region]. URL: http://volgograd.regnews.org/doc/vq/hf.htm.

11. Prokosheva E.A. Osobennosti i nekotorye problemy administrativnogo sanktsionirovaniya pri predostavlenii zemelnykh uchastkov dlya stroitelstva v usloviyakh zemelnoy reformy [Features and Some Problems of Administrative Authorization when Providing Land for Construction in the Conditions of Land Reform]. Yuridicheskiy mir, 2016, no. 7, pp. 49-52.

12. Federalnyy zakon «O vnesenii izmeneniy $\mathrm{v}$ Zemelnyy kodeks Rossiyskoy Federatsii i otdelnye zakonodatelnye akty Rossiyskoy Federatsii» ot 23 iyunya 2014 g. № 171-FZ (red. ot 29 iyulya 2017 g.) [Federal Law "On Amendments to the Land Code of the Russian Federation and Certain Legislative Acts of the Russian Federation" of June 23, 2014 no. 171-FL (as amended on July 29, 2017)]. Sobranie zakonodatelstva RF, 2014, no. 26, art. 3377.

\section{Information about the Authors}

Oksana I. Sharno, Candidate of Juridical Sciences, Associate Professor, Department of Constitutional and Municipal Law, Volgograd State University, Prosp. Universitetsky, 100, 400062 Volgograd, Russian Federation, sharnoksana@yandex.ru.

Sergey A. Frolov, Candidate of Juridical Sciences, Head of the Legal department of OP Uran-1 Ltd., Prosp. Universitetsky, 100, 400062 Volgograd, Russian Federation, frolov_sa@mail.ru.

\section{Информация об авторах}

Оксана Игоревна Шарно, кандидат юридических наук, доцент кафедры конституционного и муниципального права, Волгоградский государственный университет, просп. Университетский, 100, 400062 г. Волгоград, Российская Федерация, sharnoksana@yandex.ru.

Сергей Александрович Фролов, кандидат юридических наук, начальник юридического отдела ООО «ОП “Уран-1”», просп. Университетский, 100, 400062 г. Волгоград, Российская Федерация, frolov_sa@mail.ru. 